\title{
Vitamin $K$ prophylaxis: Leaving the old route for the new one?
}

\author{
FRANCESCO TANDOI ${ }^{1}$, FABIO MOSCA $^{2} \&$ MASSIMO AGOSTI $^{1}$ \\ ${ }^{1}$ Neonatal Intensive Care Unit, Del Ponte Hospital, Varese, Italy, ${ }^{2}$ Neonatal Intensive Care Unit, \\ Clinica Mangiagalli, University of Milan, Milan, Italy
}

\begin{abstract}
Oral or parenteral administration of vitamin $\mathrm{K}$ is the accepted practice for prevention of early vitamin $\mathrm{K}$ deficiency bleeding (VKDB) in the newborn. However, vitamin $\mathrm{K}$ prophylaxis in the newborn continues to be a worldwide health concern, particularly in breastfed infants. This paper reviews the current status of the use of vitamin $\mathrm{K}$ for the prevention of early and late VKDB.
\end{abstract}

Key Words: Vitamin K, prophylaxis, vitamin K deficiency bleeding, infancy, haemorrhagic disease of the newborn

\section{The basis of pathogenesis}

Vitamin $\mathrm{K}$ is a fat-soluble vitamin necessary for the synthesis of factors II, VII, IX and $\mathrm{X}$ in the liver. Vitamin $\mathrm{K}$ deficiency bleeding (formerly known as haemorrhagic disease of the newborn, HDN) comprises early $(0-24 \mathrm{~h})$, classic $(1-7 \mathrm{~d})$ and late $(2-12 \mathrm{wk})$ syndromes according to the time of presentation [1].

The vitamin $\mathrm{K}$ status of neonates is characterized by the following features:

(a) transplacental passage from mother to infant seems to be insignificant as proved by the almost immeasurable cord blood concentration of phylloquinone (vitamin $\mathrm{K}_{1}$ );

(b) neonates differ from adults because they have virtually no hepatic stores of menaquinones (vitamin $\mathrm{K}_{2}$ ) synthesized by specific bacteria of the gut; in fact, the intestinal microflora typical in breastfed infants (lactobacillus) do not synthesize menaquinones;

(c) in the first week of life, the original vitamin $\mathrm{K}$ deficiency is also associated with low breast milk output and with a slow build up of hepatic stores [2].

All these factors reduce the total intake of vitamin $\mathrm{K}$ in exclusively breastfed infants (US Recommended Dietary Allowances Committee recommends $1 \mu \mathrm{g} / \mathrm{kg} /$ d) and increase the risk of developing early or classic VKDB.
No single identifiable biochemical cause of late VKDB has been discovered and, although specific underlying diseases (causing malabsorption) are identified in some children, most cases are considered idiopathic. The most easily identified risk factors are the failure to give vitamin $\mathrm{K}$ prophylaxis at birth and exclusive breastfeeding. There is also evidence that some infants with late VKDB have mild and self-correcting disorders of liver function that lead to a degree of cholestasis [3].

\section{Clinical features}

Early/classic deficiency can result in unexpected bleeding $(0.25-1.7 \%$ incidence) during the first week of life in healthy neonates [4]. Clinical features are mostly represented by dark melaena stools, bloody vomit, nose bleed, blood-stained urine, petecchiae, cephaloematoma or bleeding from the umbilical stump, and circumcision bleeding; catastrophic central nervous system bleeding is infrequent. This kind of disease (especially in the first 2-3 d of life) can occur even in babies of mothers on certain anticonvulsants (phenobarbitale, carbemazepina), antibiotics (rifampicyne) or anticoagulant treatment (warfarin) [1].

The rate of late VKDB ranges from 4.4 to 7.2 per 100000 births, according to reports from Europe and Asia $[5,6]$. After a single dose of oral vitamin $\mathrm{K}$, the rate decreases to 1.4 to 6.4 per 100000 births. Late VKDB, a syndrome defined as bleeding attributable to severe

Correspondence: M. Agosti, NICU, Via "F. Del Ponte” 2, 21100 Varese, Italy. Tel/fax: + 390332 299423. E-mail: massimo.agosti@ospedale.varese.it 
vitamin $\mathrm{K}$ deficiency in infants 2 to $12 \mathrm{wk}$ of age, occurs primarily in exclusively breastfed infants who have received no or inadequate neonatal vitamin $\mathrm{K}$ prophylaxis [4].

Of major concern is the VKDB onset, sudden and unpredictable, with a high $(50-82 \%)$ frequency of intracranial haemorrhage as the presenting feature $[7,8]$. Other less common initial manifestations include ecchymosis and gastrointestinal or mucous membrane bleeding [3]. In infants who have intestinal malabsorption defects (cholestatic jaundice, cystic fibrosis, $\alpha_{1}$-antitrypsin deficiency), late VKDB may be the presenting feature of these underlying diseases [9-11].

\section{The "K" point}

Although the efficacy of neonatal vitamin $\mathrm{K}$ prophylaxis in the prevention of VKDB is firmly established, its history is not new to medical debate. The American Academy of Pediatrics has recommended a prophylactic policy, as a standard of care for newborn infants, since 1961 [12], but the concern created by Golding et al. in 1992 [13], suggesting that intramuscolar (IM) vitamin $\mathrm{K}$ might be associated with a greater incidence of later childhood malignancy, has generated much uncertainty, undermining public confidence and putting at risk potential health benefits [14].

A series of additional studies have been conducted by other investigators to verify this relationship, but unfortunately they do not completely resolved the vitamin $\mathrm{K}$-cancer dilemma: a risk of solid tumours can almost definitely be ruled out, but a small risk of leukaemia, even if hypothetical, cannot be definitely excluded (absence of evidence is not evidence of absence!) [15-19].

\section{Cutting the Gordian knot?}

At the time of the cancer warning, certain European countries, Australia and New Zealand (despite the American Academy of Pediatrics confidence in universal IM prophylaxes) adopted oral administration, but when cases of late VKBD started to reappear, some of them reverted to IM administration. All this changing generated much anxiety in the scientific community and confusion among public opinion. Moreover, confidence in IM prophylaxis became difficult to fully restore, and policy started to vary from country to country [14].

The experience of the Netherlands contributed to untying the Gordian knot of prophylaxes [20]. They formulated a radical, logical prophylaxis regimen with the same efficacy that inspired Alexander the Great's decisive solution (he cut the knot with his sword). As bottle-fed babies receive sufficient vitamin $\mathrm{K}$ in their supplemented formula to prevent VKDB (with rare exceptions, even those with liver disease are protected), it is logical to give breastfed babies an equivalent supplement of vitamin $\mathrm{K}_{1}$ (25 $\mu \mathrm{g}$ daily) $[7,20]$. This "low dose" avoids the grossly unphysiological peaks of plasma vitamin produced by the IM regimen (plasma concentration of vitamin $\mathrm{K}$ after intramuscular administration of $1 \mathrm{mg}$ exceeds endogenous levels by a factor of up to 10000 [21]), while daily dosing should circumvent the problem of infants' very limited ability to store the vitamin. Since 1992 the following regimen has been used successfully in the Netherlands: normalrisk infants receive $1 \mathrm{mg}$ vitamin $\mathrm{K}_{1}$ orally at birth (given IM to those with high-risk features) and, from $7 \mathrm{~d}$ until 3 mo of age, breastfed infants are given daily $25-\mu \mathrm{g}$ oral drops of vitamin $\mathrm{K}_{1}$ by their mothers. While it would be hard to prove that daily administration of vitamin $K_{1}$ in this way has no adverse effects, it is acceptable on the basis that it has been practised in formula feeding for many years [22].

In 1997 Cornelissen et al. confirmed the efficacy of the Dutch model (0 late VKDB in 100000 live births) in comparison with other prophylactic policies (from Switzerland, Germany and Australia). Newborns receiving incomplete oral prophylaxis tended to have a higher risk of developing $\mathrm{VKDB}$, with rates of approximately 2 to 4 per 100000 . However, this result needs to be studied more closely because of the potential sources of bias (citing the words of the authors, "... in terms of proper epidemiology [these results] can only be used to generate hypotheses to be tested in randomized clinical trials (RCT)...") [23].

Moreover, even if the Dutch experience also showed that parental administration of the daily dose is not a major problem $[21,22]$, some doubts still remain in terms of familiar compliance especially in those countries where socio-economic conditions could affect such long and expensive treatment.

\section{Some knots still to cut}

After Golding's report, concern for intramuscular (IM) administration generated a growing request for an oral preparation. It led pharmacological companies to formulate a new soluble vitamin $\mathrm{K}$, currently available, composed of vitamin $\mathrm{K}$, the phospholipid lecithin and the bile salt glycocholic acid, because vitamin $\mathrm{K}$ requires emulsification and the presence of bile salts for its absorption. The "mixed micellar" formulation, for oral use, was soon available [24]. Initially, studies showed that this new preparation was well absorbed, giving, in the first $7 \mathrm{~d}$ of life, plasma concentration equal to IM administration, and protecting from early and late VKDB; this point is still confirmed $[7,11,23,25,26]$. This superior bioavailability suggested that this preparation could also be well absorbed by infants with severe cholestasis. In a more recent prospective, randomized, controlled study, this point, 
which initially seemed to be satisfied by this preparation, was shown to be limited because of the potential severity of malabsorption in infants with cholestasis. In this group of infants, oral vitamin $\mathrm{K}$ administration may improve its status in the short term, but is insufficient to afford a buffer of reserves for longer-term protection [27].

\section{The "world" of vitamin $\mathrm{K}$}

At the present time, many differences still remain between various countries (especially between Europe and the United States) in the vitamin K administration policies for prevention of late VKBD. After analysis by the Vitamin K Ad Hoc Task Force [28] and the subsequent "Policy Statement" [4], the American Academy of Pediatrics firmly sustains the IM way, while Europe shares a constellation of treatments. This situation complicates the question impeding epidemiologists to produce univocal results without bias.

The Cochrane Library has recently reviewed RCTs present in the literature: on 17 RCTs found, 13 have been included in the meta-analysis [29]. The main questions mentioned (and the relative answers) were the following:

- Is one dose of vitamin $\mathrm{K}$, given after birth, able to significantly reduce the incidence of classic and late HDN?

- A single dose $(1.0 \mathrm{mg}$ ) of IM vitamin $\mathrm{K}$ after birth is effective in the prevention of classic HDN.

- Is there a significant difference between the oral route and the IM route in preventing classic and late HDN?

- Both IM and oral $(1.0 \mathrm{mg})$ vitamin $\mathrm{K}$ prophylaxis improve biochemical indices of coagulation status at 1-7 d. Neither IM nor oral vitamin $\mathrm{K}$ have been tested in randomized trials with respect to effect on late HDN.

- Are multiple oral doses of vitamin $\mathrm{K}$, given after birth, able to significantly reduce the incidence of classic and late HDN?

- Oral vitamin $\mathrm{K}$, in either single or multiple dose, has not been tested in randomized trials for its effect on either classic or late HDN.

None of these answers strictly address late HDN.

\section{Vitamin $K$ and preterm infants}

The efficacy of vitamin $\mathrm{K}$ prophylaxis in term infants has been proved, but only a few studies have been performed on preterm infants. For this population, data about vitamin $\mathrm{K}$ status are few, and recommended intakes are arbitrary, ranging from 5 to $10 \mu \mathrm{g} / \mathrm{kg} / \mathrm{d}$ [33] to as high as $100 \mu \mathrm{g} / \mathrm{kg} / \mathrm{d}$ [34], with current prophylaxis at birth ranging from $0.1 \mathrm{mg}$ to $1 \mathrm{mg}$ IM or intravenously [23]. The work of Kumar et al., in premature infants at $2 \mathrm{wk}$ of age, showed evidence of high plasma vitamin $\mathrm{K}$ levels (similar to those in term formula-fed infants) due to the parenteral administration of large amounts of vitamin $\mathrm{K}$; the conclusion of the above was to consider the reduction of the amount of parenteral vitamin $\mathrm{K}$ supplementation in this class of infants [35].

In the subsequent study conducted by Costakos et al., an initial dose of $0.3 \mathrm{mg} / \mathrm{kg}$ vitamin $\mathrm{K} \mathrm{IM}$ or intravenously was considered adequate for babies with birthweight below $1000 \mathrm{~g}$ [36]. But although this dosage was confirmed in both the fourth and fifth edition of AAP's Pediatric Nutrition Handbook, in the discussion of the nutritional management of the preterm infant (chapters 5 and 2 , in the respective editions), a range of doses from 0.5 to $1 \mathrm{mg} I M$ at birth was stated in later chapters [37,38]; this latter dose was used in reaffirming the efficacy of intramuscular administration over the oral route for the initial prophylaxis in recommendation 1 of the statement [4].

\section{Conclusions}

Even if it is still under debate, the question about appropriate vitamin $\mathrm{K}$ prophylaxis seems to be less problematic than some years ago. A new window, addressing physiology and safety, seems to have been opened by oral solutions, including "mixed micellar" or "low-dose" preparations. Moreover, growing interest in recent studies has revaluated the real content of vitamin $\mathrm{K}$ in human milk (apparently dependent on diet) with different bioavailability and has reconsidered the real needs of vitamin $\mathrm{K}$ in breastfed infants [3032]. These solutions could offer a good alternative for the prevention of late VKBD and improve vitamin K status in term newborn infants. For those neonates with higher haemorrhagic risk (preterm or asphyxiated infants or for those illnesses which delay feeding or inhibit vitamin $\mathrm{K}$ activity), these conclusions need to be confirmed.

\section{Acknowledgements}

Dr F. M. Tandoi gratefully acknowledges the financial support of the "Griffini-Miglierina" Foundation.

\section{References}

[1] Hathaway WE. New insights on vitamin K. Hematol Oncol Clin North Am 1987;1:367-79.

[2] Greer FR, Marshall SP, Foley AL, Suttie JW. Improving the vitamin $\mathrm{K}$ status of breastfeeding infants with maternal vitamin K supplements. Pediatrics 1997;99:88-92.

[3] Shearer MJ. Vitamin K. Lancet 1995;345:229-34.

[4] American Academy of Pediatrics, Policy Statement. Controversies concerning vitamin $\mathrm{K}$ and the newborn. Pediatrics 2003;112:191-2. 
[5] von Kries R, Hanawa Y. Neonatal vitamin K prophilaxis. Report of Scientific and Standardization Subcommittee on Perinatal Haemostasis. Thromb Haemost 1993;69:293-5.

[6] Motohara K, Endo F, Matsuda I. Screening for late neonatal vitamin $\mathrm{K}$ deficiency by acarboxyprothrombin in dried blood spots. Arch Dis Child 1985;62:370-5.

[7] von Kries R. Oral versus intramuscular phytomenadione: safety and efficacy compared. Drug Safety 1999;21:1-6.

[8] Hanawa Y, Maki M, Murata B, Matsuyama E, Yamamoto Y, Nagao T, et al. The second nation-wide survey in Japan of vitamin K deficiency in infancy. Eur J Pediatr 1988;147:472-7.

[9] Ekelund H. Late haemorrhagic disease in Sweden 1987-89. Acta Paediatr Scand 1991;80:966-8.

[10] Loughnan PM, McDougall PN. Epidemiology of late onset haemorrhagic disease: a pooled data analysis. J Paediatr Child Health 1993;29:177-81.

[11] Schubiger G, Stocker C, Banziger O, Laubscher B, Zimmerman $\mathrm{H}$. Oral vitamin $\mathrm{K}_{1}$ prophylaxis for newborns with a new mixed-micellar preparation of phylloquinone: 3 years experience in Switzerland. Eur J Pediatr 1999;158:599-602.

[12] American Academy of Pediatrics, Committee on Nutrition. Vitamin $\mathrm{K}$ compounds and the water-soluble analogues: use in therapy and prophylaxis in pediatrics. Pediatrics 1961;28: 501-7.

[13] Golding J, Greenwood R, Birmingham K, Mott M. Childhood cancer, intramuscular vitamin $\mathrm{K}$, and pethidine given during labour. Br Med J 1992;305:341-6.

[14] Hey E. Vitamin K - what, why, and when. Arch Dis Child Fetal Neonatal Ed 2003;88:F80-3.

[15] McKinney PA, Juszczak E, Findlay E, Smith K. Case-control study of childhood leukaemia and cancer in Scotland: findings for neonatal intramuscular vitamin K. Br Med J 1998;316: 173-7.

[16] Passmore SJ, Draper G, Brownbill P, Kroll M. Ecological studies of relation between hospital policies on neonatal vitamin $\mathrm{K}$ administration and subsequent occurrence of childhood cancer. Br Med J 1998;316:184-9.

[17] Parker L, Cole M, Craft AW, Hey EN. Neonatal vitamin K administration and childhood cancer in the north of England. Br Med J 1998;316:189-93.

[18] Passmore SJ, Draper G, Brownbill P, Kroll M. Case-control studies of relation between childhood cancer and neonatal vitamin $\mathrm{K}$ administration: retrospective case-control study. $\mathrm{Br}$ Med J 1998;316:178-84.

[19] Zipursky A. Vitamin K at birth: haemorrhagic disease of the newborn can be eradicated without risk of leukaemia or cancer. Br Med J 1996;313:179-80.

[20] von Kries. Neonatal vitamin K prophylaxis: the Gordian knot still awaits untying. Br Med J 1998;316:161-2.

[21] McNinch AW, Upton C, Samuels M, Shearer MJ, McCarthy P. Plasma concentrations after oral or intramuscular vitamin $\mathrm{K}$ in neonates. Arch Dis Child 1985;60:814-8.

[22] Tripp JH, Mc Ninch AW. The vitamin K debacle: cut the Gordian knot but first do not harm. Arch Dis Child 1998;79: 295-9.

[23] Cornelissen M, von Kries R, Loughnan P, Schubiger G. Prevention of vitamin $\mathrm{K}$ deficiency: efficacy of different multiple oral dose schedules of vitamin K. Eur J Pediatr 1997;156: $126-30$.
[24] Greer FR, Marshall SP, Severson RR, Smith DA, Shearer MJ, Pace DG, et al. A new mixed micellar preparation for oral vitamin $\mathrm{K}$ prophylaxis: randomised controlled comparison with an intramuscular formulation in breast fed infants. Arch Dis Child 1998;79:300-5.

[25] Tiwari $M$. Oral vitamin-K administration at birth. Indian Pediatrics 2003;40:909-10.

[26] Schubiger G, Gruter J, Shearer MJ. Plasma vitamin $\mathrm{K}_{1}$ and PIVKA-II after oral administration of mixed-micellar or cremophor EL-solubilized preparations of vitamin $\mathrm{K}_{1}$ to normal breast-fed newborns. J Pediatr Gastroenterol Nutr 1997;24: 280-4.

[27] Pereira SP, Shearer MJ, Williams R, Mieli-Vergani G. Intestinal absorption of mixed micellar phylloquinone (vitamin $\mathrm{K} 1$ ) is unreliable in infants with conjugated hyperbilirubinaemia: implications for oral prophylaxis of vitamin $\mathrm{K}$ deficiency bleeding. Arch Dis Child Fetal Neonatal Ed 2003;88: F113-8.

[28] American Academy of Pediatrics, Vitamin K Ad Hoc Task Force. Controversies concerning vitamin $\mathrm{K}$ and the newborn. Pediatrics 1993;91:1001-3.

[29] Puckett RM, Offringa M. Prophylactic vitamin K for vitamin K deficiency bleeding in neonates (Cochrane Review). In: The Cochrane Library, Issue 1, 2003. Oxford.

[30] Thjssen HH, Drittij MJ, Vermeer C, Schoffelen E. Menaquinone-4 in breast milk is derived from dietary phylloquinone. $\mathrm{Br}$ J Nutr 2002;87:219-26.

[31] Nishiguchi $T$, Yamashita $M$, Maeda $M$, Matsuyama $K$, Kobayashi $\mathrm{T}$, Kanayama N, et al. Improvement of vitamin $\mathrm{K}$ status of breastfeeding infants with maternal supplement of vitamin K2 (MK40). Semin Thromb Hemost 2002;28: 533-8.

[32] Kojima T, Asoh N, Yamawaki N, Hasegawa H, Yonekubo A. Vitamin $\mathrm{K}$ concentrations in the maternal milk of Japanese women. Acta Paediatr 2004;93:457-63.

[33] Greer FR. Vitamin K. In: Tsang RC, Lucas A, Uauy R, Zlotkin $\mathrm{S}$, editors. Nutritional needs of the preterm infant: scientific basis and practical guidelines. Baltimore, MD: Williams and Wilkins; 1993. p. 111-9.

[34] Greene H, Hambridge K, Schanler R, Tsang RC. Guidelines for the use of vitamins, trace elements, calcium, magnesium and phosphorus in infants and children receiving total parenteral nutrition: report of the Subcommittee on Pediatric Parenteral Nutrient Requirements from the Committee on Clinical Nutrition. Am J Clin Nutr 1988;48:1324-42.

[35] Kumar D, Greer FR, Super DM, Suttie JW, Moore JJ. Vitamin $\mathrm{K}$ status of premature infants: implications for current recommendations. Pediatrics 2001;108:1117-22.

[36] Costakos DT, Greer FR, Love LA, Dahlen LR, Suttie JW. Vitamin K prophylaxes for premature infants: $1 \mathrm{mg}$ versus 0.5 . Am J Perinatol 2003;20:485-90.

[37] American Academy of Pediatrics, Committee on Nutrition. Nutritional needs of preterm infant. In :Kleinman RE, editor. Pediatric nutrition handbook. 4 th ed. Elk Grove Village, IL: American Academy of Pediatrics; 1998. p. 66-8.

[38] American Academy of Pediatrics, Committee on Nutrition. Nutritional needs of preterm infant. In: Kleinman RE, editor. Pediatric nutrition handbook. 5th ed. Elk Grove Village, IL: American Academy of Pediatrics; 2004. p. 36. 